\title{
Mapeamento e análise da matrícula de estudantes com deficiência em três Universidades públicas brasileiras
}

\author{
Sandra Eli Sartoreto de Oliveira Martins \\ Universidade Estadual Paulista- Marília - SP - Brasil \\ Lúcia Pereira Leite \\ Universidade Estadual Paulista - Bauru - SP - Brasil \\ Ana Paula Camilo Ciantelli \\ Universidade Estadual Paulista - Bauru - SP - Brasil
}

\section{Resumo}

O ingresso de estudantes com deficiência no Ensino Superior se torna cada vez mais presente na realidade brasileira; porém, é difícil traçar um panorama mais real sobre o número desses estudantes e de suas demandas educacionais. Este texto retrata, de forma crítica, os índices de matrícula na graduação de estudantes com deficiência em três instituições de ensino superior públicas no país. Trata-se de um estudo longitudinal que considerou os procedimentos adotados na identificação para o ingresso e permanência desses estudantes, no intervalo de 2014-2015, levantados pela consulta da documentação das instituições. Foi traçado o perfil de graduandos com deficiência a partir da caracterização e forma de autodeclaração das deficiências instituídas pelas universidades. Percebeu-se que o número de matrículas ainda é tímido, demonstrando a necessidade de investimentos em políticas afirmativas e institucionais, para garantir a participação desse segmento na universidade pública.

Palavras-chave: Pessoas com deficiência; ensino superior; educação inclusiva.

\section{Mapping and analysis of the enrollment of students with disabilities in three Brazilian public universities}

\begin{abstract}
The enrollment of students with disabilities in Higher Education is becoming more and more present in the Brazilian reality, however, it is difficult to draw a more realistic picture about the number of these students and their educational demands. This text critically portrays the graduation rates of students with disabilities in three public higher education institutions in the country. It is a longitudinal study that considered the procedures adopted in the identification of the entry and stay of these students, in the period of 2014-2015, raised by the consultation of the documentation of the institutions. The profile of graduates with disabilities, regarding the characterization and the form of self-declaration of the deficiencies instituted in the universities. It was noticed that the number of registrations is still timid, demonstrating the need for investments in affirmative and institutional policies, to guarantee the participation of this segment in the public university.
\end{abstract}

Keywords: People with disabilities; higher education; inclusive education.

\section{Mapeo y análisis de la inscripción de estudiantes con deficiencia en tres Universidades públicas brasileñas}

\section{Resumen}

El ingreso de estudiantes con deficiencia en la Enseñanza Universitaria se vuelve cada vez más presente, en la realidad brasileña, sin embargo, es difícil elaborar un panorama más real sobre el número de esos estudiantes y de sus demandas educacionales. En este texto se describe, de forma crítica, los índices de inscripción en la graduación de estudiantes con deficiencia en tres instituciones de enseñanza superior públicas en el país. Se trata de un estudio longitudinal que llevó en cuenta los procedimientos adoptados en la identificación para el ingreso y permanencia de esos estudiantes, en el periodo de 2014-2015, recopilados por la consulta de la documentación de las instituciones. Se trazó el perfil de graduandos con deficiencia en las universidades investigadas, a pesar de la dificultad en la obtención de esos datos, cuanto a la caracterización y a la forma de auto declaración de las deficiencias instituidas en las universidades. Se percibió que el número de inscripciones aun es bajo, demostrando la necesidad de inversiones en políticas afirmativas e institucionales, para garantizar la participación de ese segmento en la universidad pública.

Palabras clave: Personas con deficiencia; enseñanza universitaria; educación inclusiva. 


\section{Introdução}

O ingresso de estudantes com deficiência no Ensino Superior se torna cada vez mais presente, na realidade brasileira, aumentando as discussões acerca dessa temática. Segundo os dados do Instituto Nacional de Estudos e Pesquisas Educacionais Anísio Teixeira - INEP (2015), o número de matrículas no ensino superior cresceu $3,5 \%$, na rede privada, e decresceu $0,4 \%$, na rede pública, nos períodos de 2014-2015, sendo que as instituições privadas concentram $75,7 \%$ das matrículas. No retrato do sistema do ensino superior público, tem-se: $62,2 \%$ das matrículas estão em instituições federais; $31,7 \%$ em instituições estaduais; $6,1 \%$ em instituições municipais, sendo que as universidades representam $53,2 \%$ das matrículas, $20,7 \%$ das quais concentradas nas públicas e $32,5 \%$, nas particulares (INEP, 2015). De acordo com esse órgão (INEP, 2015), havia 37.927 estudantes com deficiência matriculados no Ensino Superior, no ano de 2014. Desses, 22.175 (58,5\%) estavam matriculados em instituições privadas e 15.752 (41,5\%), em instituições públicas de ensino. Da parcela de estudantes matriculados em instituições públicas, 12.889 (81,9\%) estavam em instituições federais, 2.560 (16,2\%) em estaduais e $303(1,9 \%)$ em municipais.

Diante disso, observa-se, em nosso país, uma maior preocupação para o acesso e a permanência na universidade de grupos socialmente desfavorecidos, como é o caso do estudante com deficiência. Todavia, apesar do aumento de matrículas e das políticas educacionais para pessoas com deficiência deparamo-nos com uma lacuna, pois se comparadas à população geral, apenas $0,4 \%$ das matrículas no ensino superior são de estudantes com deficiência. Tais números ainda se mostram pouco expressivos, mesmo com a adoção de políticas públicas que direcionam para a inclusão de pessoas com deficiência no ensino superior, como o Decreto n 6.949/09 (2009), o qual assegura o acesso ao sistema educacional em todos os níveis de ensino, tendo como meta a participação em ambientes que maximizem o desenvolvimento acadêmico e social.

De acordo com a atual Lei Brasileira de Inclusão da Pessoa com Deficiência - Estatuto da Pessoa com Deficiência (Lei n 13.146, 2015), em seu Artigo $2^{\circ}$,

considera-se pessoa com deficiência aquela que tem impedimento de longo prazo de natureza física, mental, intelectual ou sensorial, o qual, em interação com uma ou mais barreiras, pode obstruir sua participação plena e efetiva na sociedade em igualdade de condições com as demais pessoas.

Essa conceituação foi apresentada anteriormente pelo Decreto n 6.949/09 (2009), que ratifica, no Brasil, os dispositivos da Convenção da ONU sobre os Direitos da Pessoa com Deficiência, de sorte que o Estatuto reitera que a deficiência não deve ser mais vista como algo intrínseco à pessoa, mas presente e de responsabilidade da sociedade, sendo essa responsável por superar a deficiência por meio da eliminação das barreiras existentes no ambiente (barreiras urbanísticas, arquitetônicas, atitudinais, tecnológicas, nas comunicações e informações e nos transportes) e da criação de mecanismos e recursos que possibilitem a plena e efetiva participação dessas pessoas na sociedade. Ao assumir essas premissas, defende-se um modelo social de deficiência que busca superar o modelo biomédico clínico da normalidade, respeitando a diversidade humana, independentemente das diferentes limitações funcionais existentes no indivíduo.

Na Lei Brasileira de Inclusão, a educação é tida como um direito da pessoa com deficiência, assegurando um sistema educacional em todos os níveis e aprendizado ao longo de toda a vida, de forma que o aluno possa alcançar o máximo desenvolvimento possível de seus talentos e habilidades físicas, sensoriais, intelectuais e sociais, segundo suas características, interesses e necessidades de aprendizagem (Lei n 13.146, 2015).

Portanto, é direito da pessoa com deficiência o acesso ao Ensino Superior, pois, segundo o Art. 28 do Estatuto da Pessoa com Deficiência (Lei $n^{\circ} 13.146,2015$ ), incumbe ao poder público assegurar, criar, desenvolver, implementar, incentivar, acompanhar e avaliar o "XIII acesso à educação superior e à educação profissional e tecnológica em igualdade de oportunidades e condições com as demais pessoas".

Ao se retomar às políticas voltadas para a inclusão no Ensino Superior, tem-se que, a partir da segunda metade da década de 1990, ocorreram mudanças importantes no Ensino Superior brasileiro, as quais visam a possibilitar à pessoa com deficiência a garantia do direito de cursar níveis mais elevados de Ensino.

Destaca-se, nesse sentido, inicialmente, a Portaria de $n^{\circ}$ 1.679/99 (1999), que veio a contribuir para que condições de acesso fossem oferecidas à pessoa com deficiência, no Ensino Superior, assim como propagou o processo de autorização, reconhecimento e credenciamento das IES. Com sua substituição pela Portaria $n^{\circ} 3.284 / 2003$ (2003), fica estabelecido, entre outros aspectos, que o acesso do estudante com deficiência ao ensino superior deve ser garantido em todas as instituições, quer públicas, quer privadas, permitindo, assim, a permanência do estudante em cursos de graduação.

De maneira complementar, o Decreto 5.296/04 (2004) estabelece as normas gerais e critérios básicos para o atendimento prioritário à acessibilidade da PCD ou com mobilidade reduzida. Em seu art. 24, determina que os estabelecimentos de qualquer nível, etapa ou modalidade, públicos e privados, devem proporcionar condições de acesso e utilização a todos os ambientes universitários.

Pensando em criar políticas de acesso que beneficiassem diretamente as PCD, em 2005, o governo federal cria o Programa Universidade para Todos (PROUNI - Lei ${ }^{\circ}$ 11.096, 2005) e, em 2008, a Política Nacional de Educação Especial na perspectiva da Educação Inclusiva (Brasil, 2008), que dispõe sobre a transversalidade da Educação Especial e aponta que as suas ações - no ensino superior - devem proporcionar o acesso, a permanência e a participação dos estudantes, com vistas à [...] "organização de recursos e serviços para a promoção da acessibilidade arquitetônica, nas 
comunicações, nos sistemas de informação, nos materiais didáticos e pedagógicos".

Entretanto, apesar das políticas existentes em favor do estudante com deficiência no Ensino Superior brasileiro, muito há que se fazer para que de fato haja acesso, permanência e participação desses estudantes a fim de se promover uma educação igualitária, justa que atenda às necessidades especiais de cada sujeito garantindo o seu desenvolvimento acadêmico e social.

De acordo com Moreira (2004, p. 5), é grande a escassez de estudos sobre inclusão do estudante com deficiência no ensino superior brasileiro, assim como são raras as instituições que possuem mapeamento e/ou acompanhamento desse alunado. A autora aponta a necessidade de estudos nessa área, tendo em vista a demanda desses estudantes na universidade. Como exemplos de pesquisas recentes que abordaram a temática, destacam-se os estudos de Ciantelli (2015), que objetivou analisar as ações desenvolvidas pelos núcleos de acessibilidade nas Universidades Federais brasileiras, com ênfase na atuação da Psicologia em prol da participação de estudantes com deficiência no ensino superior; Branco (2015), que analisou os suportes e as barreiras de acessibilidade encontradas pelos estudantes com deficiência, diante da sua participação no Ensino Superior de Pós-Graduação, na Universidade Estadual Paulista (UNESP); Silva (2016), que teve como finalidade examinar como universitários com deficiência analisam as condições de acessibilidade e identificam o conceito de acessibilidade em três universidades públicas brasileiras; e Garcia (2016), que objetivou compreender como os acadêmicos com deficiência e/ou mobilidade reduzida conceituam as condições de acessibilidade da Universidade Estadual de Maringá (UEM). No entanto, são poucos os estudos que retratam um panorama institucional dos estudantes com deficiência matriculados no Ensino Superior.

As pesquisas relatadas derivam do projeto em rede denominado "Acessibilidade no Ensino Superior: da análise das políticas públicas educacionais ao desenvolvimento de mídias instrumentais sobre deficiência e inclusão", sob a chancela do Programa Observatório da Educação - CAPES (Edital 49/2012 - Proc. No 23038.002628/2013-41). Seus proponentes debruçaram-se a investigar as normativas e as políticas educacionais brasileiras direcionadas ao acesso e à permanência de pessoas com deficiência no ensino superior, a fim de avaliar os efeitos dessas políticas na formação inicial de professores e no desenvolvimento de recursos midiáticos focando esta temática. Integraram a rede de pesquisa 26 investigadores, 78 alunos de graduação, 28 alunos de pós-graduação de diferentes universidades públicas brasileiras, 26 professores de rede da educação básica, 8 colaboradores, 4 voluntários, totalizando uma equipe composta por 170 pessoas. Desses, 125 participantes (estudantes da graduação, pós-graduação e professores de rede e coordenação) foram contemplados com bolsa, nas modalidades: coordenação, iniciação científica, professores da rede pública, mestrado e doutorado ${ }^{1}$.

1 Mais informações sobre as pesquisas desenvolvidas pelos profissionais desta rede podem obtidos no site: www.marilia.unesp. br/acessibilidade.
Com base nas dificuldades retratadas pela equipe para traçar o perfil dos estudantes na Educação Superior, o artigo objetivou analisar o índice de matricula de estudantes com deficiência nas instituições pesquisadas - UFSC, UFSCar e UNESP, proponentes da rede de pesquisa ora mencionada. Posto isso, seus resultados servem para ampliar as reflexões sobre os procedimentos institucionais adotados no delineamento do perfil e demandas educativas especiais de universitários com deficiência em atendimento às Políticas Públicas dirigidas a orientar o acesso e à formação educacional dos que se encontram nesta condição.

\section{Método}

Trata-se de um estudo longitudinal, com início no ano de 2013 e término no ano de 2016, o qual envolveu a participação de três universidades públicas, que fizeram parte da rede de pesquisa do projeto supracitada. Cada universidade participante - no caso três: UNESP, UFSC e UFSCar -, devido a suas particularidades, encontrou uma maneira diferente de conseguir mapear esses estudantes, sendo, portanto, descrito o procedimento de coleta de dados separadamente de cada uma delas.

A UNESP é constituída por 32 unidades, localizadas em 24 municípios do Estado de São Paulo, no Brasil. Essa Instituição de Educação Superior - IES - oferece 155 cursos de graduação e 255 programas de pós-graduação, em diversas áreas do conhecimento, além de cursos pré-vestibulares gratuitos e diversos programas de extensão de serviços à comunidade. Oferta, ainda, ensino técnico em escolas mantidas pela universidade (UNESP, 2016).

Segundo os dados divulgados no sítio eletrônico da instituição, a UFSCar foi fundada em 1968 e possui quatro campi (São Carlos, Sorocaba, Araras e Lagoa do Sino), sendo que o principal se encontra em São Carlos, município localizado no interior do Estado de São Paulo. Os 48 departamentos acadêmicos da Universidade estão divididos em oito centros: Ciências Agrárias, Ciências Biológicas e da Saúde, Ciências em Gestão e Tecnologia, Ciências e Tecnologias para a Sustentabilidade, Ciências Exatas e de Tecnologia, Ciências Humanas e Biológicas, Educação e Ciências Humanas e Ciências da Natureza, oferecendo 62 cursos.

A UFSC foi fundada em 1960 e conta com 11 centros de ensino, localizados em quatro cidades: Florianópolis, Araranguá, Curitibanos e Joinville. A UFSC tem 103 cursos de graduação presenciais e 14 cursos de educação à distância, além de 63 mestrados acadêmicos, 15 mestrados profissionais, 55 cursos de doutorado e 32 cursos de especialização, de acordo com os dados disponibilizados no site da universidade.

\section{Procedimento de coleta de dados}

O mapeamento de estudantes com deficiência se configurou como um dos objetivos da rede de pesquisa do Obeduc Acessibilidade no Ensino Superior, mencionada anteriormente. 
Desse modo, a coleta descrita neste texto fez parte das ações dos pesquisadores envolvidos com a rede, nas três instituições mencionadas, as quais envolveram percursos distintos.

$\mathrm{Na}$ UNESP, o índice de matrícula desse público na graduação foi obtido por meio de um formulário, elaborado por Martins, Leite, Silva e Hashimoto (2014), com base nas orientações do Censo da Educação Superior (INEP, 2013b), aplicado na ocasião da matrícula referente ao primeiro semestre de 2014 e nos semestres subsequentes. O formulário foi disponibilizado em ambiente eletrônico, em sítio da própria instituição - responsável por armazenar os dados dos acadêmicos. O preenchimento foi obrigatório para todos os estudantes de graduação, em todas as unidades universitárias. Os respondentes preencheram individualmente o referido formulário, indicando as necessidades educacionais especiais, quando houvesse.

$\mathrm{Na}$ UFSCar, para a coleta de dados, foi construído roteiro de entrevista semiestruturada, aplicado junto à Pró-Reitoria de Graduação da Universidade, de forma a acessar os dados censitários entre o período de 2014 a 2015 da universidade. $\mathrm{Na}$ ocasião, identificou-se que a instituição ainda não possuía um banco de dados sistematizado que abrangesse os estudantes com deficiência anterior ao ano de 2014. Porém, o sistema eletrônico de matrículas, denominado ProgradWeb, vem passando por um processo de readequação. Assim como a UNESP, a UFSCar procurou ajustar o cadastramento dos estudantes com deficiência na universidade, com base nas orientações do Censo da Educação Superior (INEP, 2013b), porém, ainda não estava implementado; assim, somente forneceu uma listagem com dados de alunos que presencialmente declararam nessa condição especial junto à Prograd, segundo Battistella e Lourenço (2015). Em função da composição da amostragem, as pesquisadoras consideraram oportuno solicitar junto às coordenações de curso de graduação informações quanto ao conhecimento de estudantes público-alvo da Educação Especial, matriculados em seus respectivos cursos. Foi realizado, também, contato presencial com a chefe do departamento de serviço social da Proace - Pró-Reitoria de Assuntos Comunitários e Estudantis - com o intuito de coletar informações sobre esses estudantes, na instituição (Battistella \& Lourenço, 2015).

Conforme Santana, Donida e Pottmeier (2016), o mapeamento de estudantes com deficiência matriculados na UFSC se deu a partir das informações solicitadas junto ao CAE (Coordenadoria de Acessibilidade Estudantil). Esses dados são coletados pelo CAE, com base em duas situações: a) Controle Acadêmico da Graduação (CAGR) e Controle Acadêmico da Pós-Graduação (CAGP). Nesse caso, ao fazerem a matrícula, os alunos se autoidentificam com deficiências ou necessidades especiais. Com esses elementos, o CAE entra em contato com o aluno, via e-mail, e confirma essa informação, assim como explica os atendimentos realizados por esse setor; b) Solicitação de recurso de acessibilidade para o vestibular feita pelo estudante, no ato da inscrição. Os estudantes que reivindicam recursos especiais são também contatados, para que se possa identificar qual sua necessidade especial.

\section{Resultados}

Na leitura detalhada dos relatórios examinados, correspondentes ao mapeamento de estudantes com deficiência na UNESP, UFSCar e UFSC, percebeu-se a ausência de um modelo único para o levantamento da amostragem desse público. Tal constatação revela a autonomia universitária para recolhimento, a fim de atender à solicitação do INEP, na composição desses dados no Ensino Superior (INEP, 2013b), considerado obrigatório apenas recentemente. Os resultados que seguem serão apresentados pontualmente por IES, correspondendo aos levantamentos de matrículas efetivadas no primeiro e/ou segundo semestre letivo de 2015.

Na UNESP, em 2015, dos 35.420 estudantes matriculados, 120 se autodeclararam com deficiência, o que representa 0,33\%. Na UFSCar, foram 117 estudantes com deficiência, matriculados no primeiro semestre de 2015, de um total de 13.013 , representando $0,89 \%$ das matrículas. $\mathrm{Na}$ UFSC, 98 estudantes com deficiência estavam regularmente matriculados no segundo semestre de 2015, diante de um total de 25.894, correspondendo a 0,37\%.

Em relação ao perfil desses estudantes autodeclarados, vale enfatizar que cada universidade participante possui uma forma de classificação sobre a condição declarada, conforme observado nas tabelas a seguir.

Os dados revelam maior incidência de pessoas que se autodeclararam na categoria outras deficiências, com um total de 58 estudantes, representando $40 \%$ da amostra. Ressalta-se que, nessa categoria, os dados que se sobressaíram foram os transtornos funcionais específicos (TDAH e Dislexia) e alguns transtornos mentais (Transtorno do pânico, Transtorno de ansiedade, Transtorno bipolar e depressão). Em seguida temos 28 estudantes com deficiência física, o que corresponde a $19 \%$ da amostra. A categoria "outras síndromes" foi identificada por 13 estudantes, com destaque para a Síndrome do Pânico, de Borderline, de Ehler-Donlus, de Marfan e Treacher Collins. A visão subnormal foi autodeclarada por 13 estudantes, seguida da deficiência múltipla, informada por 11 estudantes, a deficiência intelectual, por nove estudantes, e o transtorno do espectro autista, por oito estudantes; com menor número, a cegueira e a deficiência auditiva, com dois estudantes. As categorias surdez e surdocegueira não foram citadas por nenhum respondente.

De acordo com a Tabela 2, correspondente aos dados da UFSCar, houve uma maior incidência de estudantes que se declararam com deficiência auditiva, com um total de 65 estudantes (55\%), em seguida, 21 estudantes (18\%) que se declararam com outras necessidades não especificadas, 20 com baixa visão ou visão subnormal, oito estudantes com deficiência física, um com cegueira, e, em igual número, com condutas típicas e com deficiência intelectual.

De acordo com os dados da Tabela 3, que correspondem aos da UFSC, houve uma maior incidência de estudantes que se declararam com surdez, com um total de 35 estudantes (36\%), em seguida, 16 estudantes com deficiência física, 15 com deficiência auditiva, 11 com deficiência visual, oito com paralisia cerebral, sete com Síndrome do Espectro 
Tabela 1. Categoria de deficiência dos estudantes da UNESP.

\begin{tabular}{ccc}
\hline Deficiência & Dados absolutos $(\mathrm{N})$ & Dados relativos (\%) \\
\hline Cegueira & 3 & 2 \\
Deficiência Auditiva & 2 & 8 \\
Deficiência Múltipla & 11 & 6 \\
Deficiência Intelectual & 9 & 19 \\
Deficiências Física & 28 & 40 \\
Outras Deficiências & 58 & 9 \\
Outras Síndromes & 13 & 6 \\
Transtorno do Espectro Autista & 8 & 9 \\
Visão Subnormal & 13 & 100
\end{tabular}

Fonte: Dados do relatório da pesquisa de Ciantelli, Leite e Martins (2016).

*Ressalta-se que, devido ao estudante poder se autodeclarar com mais de uma deficiência, no formulário, como no caso da deficiência múltipla, outras deficiências e outras síndromes, o número total de deficiências ultrapassa o número total de estudantes que se autodeclaram com deficiência, nessa universidade.

Tabela 2. Categorias de deficiência dos estudantes da UFSCar.

\begin{tabular}{ccc}
\hline Deficiência & Dados absolutos $(\mathrm{N})$ & Dados relativos (\%) \\
\hline Baixa visão & 20 & 17 \\
Cegueira & 1 & 1 \\
Condutas Típicas & 1 & 55 \\
Deficiência auditiva & 65 & 7 \\
Deficiência física & 8 & 1 \\
Deficiência intelectual & 1 & 18 \\
Outras necessidades & 21 & 100 \\
\hline Total & 117 & 1 \\
\hline
\end{tabular}

Fonte: Dados extraídos do relatório da pesquisa de Battistella \& Lourenço (2015)

Tabela 3. Categorias de deficiência dos estudantes da UFSC.

\begin{tabular}{ccc}
\hline Deficiência & Dados absolutos (FN) & Dados relativos (\%) \\
\hline Deficiência auditiva & 15 & 15 \\
Deficiência física & 16 & 16 \\
Deficiência múltipla & 1 & 1 \\
Deficiência visual & 11 & 11 \\
Paralisia cerebral & 8 & 8 \\
Síndrome de Down & 1 & 1 \\
Síndrome do Espectro Autista & 7 & 7 \\
Síndrome Mearslrlen & 1 & 1 \\
Síndrome Prader-Willi & 1 & 1 \\
Surdez & 35 & 37 \\
Surdocegueira & 2 & 2 \\
\hline Total & 98 & 100 \\
\hline
\end{tabular}

Fonte: Dados extraídos do relatório da pesquisa de Santana e cols. (2016). 
Autista, dois com surdocegueira, um com deficiência múltipla, um estudante com osteogênese imperfeita, em igual número com Síndrome de Down, Síndrome de Mears Irlen e com Síndrome Prader-Willi.

\section{Discussão}

A partir da análise dos dados obtidos pelos mapeamentos de estudantes com deficiência, nas três universidades investigadas (UNESP, UFSCar e UFSC), percebe-se um avanço ainda tímido desse público, no Ensino Superior, visto que nem representam um por cento da amostra total de matrículas das IES. Esse dado reitera a necessidade de se garantir providências que sejam capazes de potencializar o acesso aos ambientes de ensino, favorecendo seu ingresso e participação no meio universitário.

O número pouco expressivo da matrícula de estudantes com deficiência pode estar relacionado à precariedade do desempenho do vestibulando no exame; à falta de informação e cumprimento das normativas que regem o vestibular acessível no Ensino Superior público e de acessibilidade para realizar os exames vestibulares, pois, muitas vezes, as adequações estruturais, metodológicas e/ou comunicacionais são precárias (Ciantelli, Leite, \& Martins, 2015).

Em particular chama a atenção, nos dados da UNESP, a utilização das categorias "outras deficiências" e "outras síndromes", no formulário do sistema de graduação para identificação do público em questão. Embora o campo tenha sido criado para informar outros tipos de deficiência ou síndrome não categorizados pelo formulário, o seu preenchimento pelos usuários com dislexia, TDHA, miopia, Síndrome do pânico, entre outras, descaracterizou a identificação de estudantes em condições clínicas diferenciadas fora do campo da deficiência. Todavia, de acordo com as orientações da Secretaria de Educação Continuada, Alfabetização, Diversidade e Inclusão, por meio da Diretoria de Políticas de Educação Especial (SECADI/ DPEE), estudantes que apresentam transtornos funcionais específicos, tais como TDA -Transtorno de Déficit de Atenção, TDHA - Transtorno de Déficit de Atenção - Hiperatividade, Dislexia não fazem parte do público-alvo da educação especial (São Paulo, 2012). Entretanto, vale ressaltar que, segundo a Política Nacional de Educação Especial na Perspectiva da Educação Inclusiva (Portaria Ministerial No 555, 2007) os estudantes com Transtornos Funcionais Específicos (Transtorno do Déficit de Atenção/Hiperatividade - TDAH, Dislexia, Discalculia, Disortografia, Disgrafia, Dislalia, Transtorno de Conduta e Distúrbio do Processamento Auditivo Central - DPAC), apesar de não serem considerados como público-alvo da Educação Especial, podem receber atenção educacional de professores da Educação Especial, numa articulação com demais professores da Escola Comum (Brasil, 2009; 2011).

Por sua vez, na UFSCar, o indicativo de 65 estudantes com deficiência auditiva causa estranhamento. No entanto, na leitura do relatório de Battistella e Lourenço (2015), fica evidenciado que a localização de estudantes com defici- ência ainda estava em processo de elaboração, o que pode ter gerado números imprecisos, uma vez que as autoras apontam a supernotificação, nesse caso. Percebe-se uma diferença no uso de categorização (nomenclatura) das deficiências nos mapeamentos de uma universidade para outra, a exemplo da UFSC, que especifica diferentes síndromes e o termo "paralisia cerebral", como um modo separado da deficiência física ou, ainda, a Síndrome do Espectro Autista, ao invés de utilizar Transtorno do Espectro do Autismo - TEA, conforme o V Manual Diagnóstico e Estatístico de Transtornos Mentais (DSM - 5, APA, 2015).

O uso de alguns termos inadequados para designar pessoas com deficiência ainda tem sido recorrente: a título de exemplificação, observe-se a nomenclatura "condutas típicas", na UFSCar. Essa nomenclatura passou a ser adotada a partir da década de 90 e faz referência a alunos que apresentem manifestações típicas de síndromes e quadros neurológicos, psicológicos ou psiquiátricos persistentes que ocasionam atrasos no desenvolvimento e prejuízos no relacionamento social, em grau que requeira atendimento educacional especializado. O termo "condutas típicas" abrange uma diversidade muito grande de leituras diagnósticas, impossibilitando que sejam discriminados alguns importantes pontos referentes a cada uma delas. Segundo Facion e Giannini (2002), o termo faz com que surjam alguns questionamentos, como: "típicas do que?" e "o que é típico?" Ademais, sendo típico um conjunto de características esperadas de determinado grupo classificatório, citar "condutas típicas" pede a identificação do grupo referência, o que implica ir contra os princípios da inclusão, voltando-se à ideia de "falta", de "desvio", de "anormalidade", a qual, associada aos conceitos negativos atribuídos a esse público, dificulta a sua participação no meio social.

Contudo, nota-se a grande dificuldade, por parte das Instituições pesquisadas, em realizar o mapeamento desse público, fato descrito no procedimento de coleta de dados deste artigo. Dito de outra forma, os pesquisadores apontaram procedimentos variados e muitas vezes ainda não sistematizados para localizar os estudantes com deficiência. Tal fato pode estar relacionado aos seguintes aspectos: a) a participação de pessoas com deficiência no ensino superior público brasileiro é recente, segundo os dados disponibilizados pelo Censo do Ensino Superior do INEP, conforme descrito no estudo de Martins, Leite e Lacerda (2015); b) a obrigatoriedade de as IES prestarem informações ao INEP sobre as matrículas desse público, a partir de 2014 (INEP, 2013a), construindo-se um procedimento novo, apesar de normativa anterior já ter orientado essa conduta, conforme Decreto $n^{\circ}$ 6.425/2008 (2008), o qual instituiu a obrigatoriedade, por parte das IES, em relação à prestação de informações ao Censo, e a Portaria Normativa $n^{\circ} 40$, de 12 de dezembro de 2007, republicada em 29 de dezembro de 2010, tornar informações do Cadastro e-MEC como base de dados de referência a ser utilizada no Censo do Ensino Superior. Com a divulgação dos dados concretizados do Censo, a informação prestada pelas IES passa a figurar como estatística oficial; c) a autodeclaração adotada como 
procedimento exclusivo para identificação desse público - o uso dessa ferramenta pode demonstrar a fragilidade dos dados, ou seja, deixar de retratar a realidade de cada contexto universitário, podendo subnotificar ou supernotificar o índice de estudantes com deficiência.

De acordo com os achados de Alencar (2013), muitos estudantes não se declaram como deficientes, pois não se aceitam enquanto tal e/ou porque enfrentaram tantas barreiras para chegar à universidade, que não consideram sua deficiência como um impedimento e se sentem preparados para enfrentar o desafio do ensino superior, de modo autônomo. Essa situação é evidenciada nos relatos de um dos estudantes com deficiência participante da pesquisa efetuada por Alencar (2013, p. 99):

As pessoas que conseguiram sucesso, e aí vamos dizer que quem está aqui dentro são pessoas diferenciadas, que obtiveram sucesso, essas pessoas não querem se colocar deficientes... E aí eu vou dar meu parecer, eu também acho que, se a pessoa não se sente à vontade de dizer que ele é um deficiente, ele não precisa carregar este rótulo se ele não quer.

Por fim, faz-se necessário que as instituições invistam na criação de procedimentos acadêmicos que permitam identificar semestralmente quem são esses estudantes, em que cursos estão matriculados, qual a sua deficiência e quais são as adaptações e os ajustes educacionais desejáveis para o desenvolvimento acadêmico nos contextos investigados.

\section{Considerações Finais}

O presente estudo objetivou descrever e analisar o mapeamento de estudantes com deficiência matriculados no ensino superior, em três instituições públicas - Universidade Estadual Paulista (UNESP), Universidade Federal de São Carlos (UFSCar) e Universidade Federal de Santa Catarina (UFSC) -, de forma a demonstrar a participação desse público nessa etapa de educação.

Ao realizar o mapeamento dos estudantes com deficiência dessas Universidades, percebeu-se um avanço ainda tímido no que se refere à participação de pessoas com deficiência, nessas instituições, visto que, em todas, nem um por cento do total de matrículas é ocupado por esse público. Esse dado indica a necessidade de estudos complementares capazes de explicitar os motivos da inexpressividade de matrículas. Todavia, enfatiza-se que, apesar de baixos, esses números vêm crescendo anualmente, devido aos investimentos em políticas afirmativas e institucionais pela participação desse público no Ensino Superior.

A dificuldade na identificação desses estudantes nas Universidades é algo que merece muita atenção, pois a falta mapeamento fidedigno pode acarretar em dados imprecisos da presença desse público e, consequentemente, na dificuldade em prover os atendimentos e ajustes necessários às suas demandas específicas. A criação de um meio de comunicação mais eficaz entre o estudante com deficiência e a instituição pode contribuir para a eliminação de diferentes barreiras, atitudinais, metodológicas, físicas, comunicacionais, no contexto acadêmico, de maneira que estes se sintam aceitos e respeitados nos seus direitos como qualquer cidadão.

Por fim, estudos que retratem a participação de pessoas com deficiência na universidade pública brasileira, como o aqui retratado, mostram-se essenciais, com os preceitos da Lei Brasileira de Inclusão da Pessoa com Deficiência (Lei n 13.146, 2015), que, em seu Art. 28, parágrafo II, já incumbe o poder público de criar, desenvolver, implementar, incentivar, acompanhar, assegurar e avaliar: "Il aprimoramento dos sistemas educacionais, visando a garantir condições de acesso, permanência, participação e aprendizagem, por meio da oferta de serviços e de recursos de acessibilidade que eliminem as barreiras e promovam a inclusão plena".

\section{Referências}

Alencar, P.M.M. (2013). Acessibilidade no Ensino Superior: o caso da UFJF. Dissertação de Mestrado em Gestão e Avaliação da Educação Pública, Universidade Federal de Juiz de Fora, Juiz de Fora.

American Psychiatric Association [APA]. (2014). Diagnostic and Statistical Manual of Mental Disorders (5th ed.) Text Revision (DSM-V-TR). Washington, DC: American Psychiatric Association.

Battistella, J.; Lourenço, G.F. (2015). Proposta de construção de um banco de dados sobre alunos com deficiência na Universidade Federal de São Carlos. Relatório Científico de Pesquisa Acessibilidade no Ensino Superior. (Relatório de pesquisa). UFSCAR-São Carlos: OBEDUC/CAPES,.

Branco, A.P.S.C. (2015). Análise das condições de acessibilidade no Ensino Superior: um estudo com Pós-Graduandos. Dissertação de Mestrado em Psicologia do Desenvolvimento e da Aprendizagem, Universidade Estadual Paulista, Faculdade de Ciências, Bauru.

Ciantelli, A.P.C. (2015). Estudantes com deficiência na Universidade: contribuições da psicologia para as ações do núcleo de acessibilidade. Dissertação de Mestrado em Psicologia do Desenvolvimento e da Aprendizagem, Universidade Estadual Paulista, Faculdade de Ciências, Bauru.

Ciantelli, A.P.C.; Leite, L.P.; Martins, S.E.S.O. (2015). Inclusão no Ensino Superior: mapeamento e análise da matrícula de alunos com deficiência e/ou mobilidade reduzida na Unesp. In: Mendes, E.G.; Almeida, M.A. (Orgs.), Educação especial inclusiva: legados históricos e perspectivas futuras (pp. 287-302). São Carlos: Marquezine \& Manzini, ABPEE.

Ciantelli, A.P.C.; Leite. L.P.; Martins, S.E.S.O. (2016). Mapeamento de alunos com deficiência na Unesp. (Relatório Científico). 
Acessibilidade no Ensino Superior- OBEDUC/CAPES.

Decreto $n^{\circ}$ 5.296, de 2 de dezembro de 2004 (2004, 2 de dezembro). Regulamenta as Leis nos 10.048 , de 8 de novembro de 2000 , que dá prioridade de atendimento às pessoas que especifica, e 10.098, de 19 de dezembro de 2000, que estabelece normas gerais e critérios básicos para a promoção da acessibilidade das pessoas portadoras de deficiência ou com mobilidade reduzida, e dá outras providências. Brasília: Presidência da República. Recuperado: 15 mai. 2014. Disponível: http://www.planalto.gov.br/ ccivil_03/_ato2004-2006/2004/decreto/d5296.htm.

Decreto $n^{\circ}$ 6.425, de 4 de abril de 2008 (2008, 4 de abril). Dispõe sobre o censo anual da educação. Brasília: Presidência da República. Recuperado: 15 maio 2013. Disponível: http://www. planalto.gov.br/ccivil_03/_ato2007-2010/2008/decreto/d6425.htm

Decreto $n^{\circ}$ 6.949, de 25 de agosto de 2009 (2009, 25 de agosto). Promulga a Convenção Internacional sobre os Direitos das Pessoas com Deficiência e seu Protocolo Facultativo, assinados em Nova York, em 30 de março de 2007. Brasília: Presidência da República. Recuperado: 17 mai. 2014. Disponível: http://www. planalto.gov.br/ccivil_03/_ato2007-2010/2009/decreto/d6949.htm.

Decreto $N^{\circ}$ 7.611, 17 novembro de 2011 (2011, 17 de novembro). Dispõe sobre a educação especial, o atendimento educacional especializado e dá outras providências. Brasília, Presidência da República. Casa Civil. Subchefia para Assuntos Jurídicos. (2011). Recuperado: 25 jan. 2018. Disponível: http://www.planalto.gov.br/ ccivil_03/_ato2011-2014/2011/decreto/d7611.htm

Facion, J.R.; Gianninni, E.F. (2002). O Processo Educacional do Aluno com Condutas Típicas. Trabalho apresentado na $6^{a}$. Jornada de Educação Especial, Marília - São Paulo.

Garcia, R.A.B. (2016). Acessibilidade no Ensino Superior na Perspectiva de Alunos com Deficiência: contribuições da Psicologia Escolar à luz da Teoria Histórico-Cultural. Dissertação de Mestrado em Psicologia, Universidade Estadual de Maringá, Maringá-PR.

Instituto Nacional de Estudos e Pesquisas Educacionais Anísio Teixeira Censo da Educação Superior [INEP] (2013a). Resumo Técnico Censo da Educação Superior. Brasília: INEP, Ministério da Educação

Instituto Nacional de Estudos e Pesquisas Educacionais Anísio Teixeira Censo da Educação Superior [INEP] (2013b). Censo da educação superior: Questionário - aluno. Brasília: INEP, Ministério da Educação. Disponível: http://portal.inep.gov.br/web/censo-daeducacao-superior/questionarios-e-manuais. Recuperado: 14 fev. 2017.

Instituto Nacional de Estudos e Pesquisas Educacionais Anísio Teixeira Censo da Educação Superior [INEP] (2015). Resumo Técnico Censo da Educação Superior. Brasília: INEP, Ministério da Educação.
Lei no 11.096, de 13 de janeiro de 2005 (2005, 13 de janeiro). Institui o Programa Universidade para Todos - PROUNI, regula a atuação de entidades beneficentes de assistência social no ensino superior; altera a Lei no 10.891, de 9 de julho de 2004, e dá outras providências. Brasília: Presidência da República. Recuperado: 15 maio 2017. Disponível: http://www.planalto.gov.br/ccivil_03/_ ato2004-2006/2005/lei/L11096.htm.

Lei $n^{\circ}$ 13.146, de 6 de julho de 2015 (2015, 6 de julho). Lei Brasileira de Inclusão da Pessoa com Deficiência (Estatuto da Pessoa com Deficiência). Recuperado: 12 jan. 2017. Disponível: http://www. planalto.gov.br/ccivil_03/_Ato2015-2018/2015/Lei/L13146.htm.

Martins, D.A.; Leite, L.P.; Lacerda, C. B.F. (2015). Políticas públicas para acesso de pessoas com deficiência ao ensino superior brasileiro: uma análise de indicadores educacionais. Ensaio: Avaliação e Políticas Públicas em Educação, 23(89), 984-1014.

Martins, S.E.S.O.; Leite, L.P.; Silva, K.C.; Hashimoto, M.S. (2014) Formulário de Identificação de Estudantes com Deficiência, Transtornos e Altas Habilidades. Seção de Graduação. (Documento interno). Faculdade de Ciências/UNESP - Obeduc/ CAPES.

Moreira, L.C. (2004). Universidade e alunos com necessidades educacionais especiais: das ações institucionais às práticas pedagógicas. Tese de Doutorado em Educação, Universidade de São Paulo, São Paulo.

Portaria . $^{\circ} 1.679$, de 2 de dezembro de 1999 (1999, 2 de dezembro). Dispõe sobre requisitos de acessibilidade de pessoas portadoras de deficiência para instruir processos de autorização e de reconhecimento de cursos, e de credenciamento de instituições. Brasília: Diário Oficial da União. n.231-E, p.20-21, Seção 1.

Portaria Federal $n^{\circ}$ 3.284, de 7 de novembro de 2003 (2003, 7 de novembro). Dispõe sobre requisitos de acessibilidade de pessoas portadoras de deficiências, para instruir os processos de autorização e de reconhecimento de cursos, e de credenciamento de instituições. Brasília: Ministério da Educação. Recuperado: 15 mai. 2013. Disponível: http://portal.mec.gov.br/seesp/arquivos/pdf/ port3284.pdf.

Portaria Normativa $n^{\circ}$ 40, de 12 de dezembro de 2007 (2007, 12 de dezembro). Institui o e-MEC, sistema eletrônico de fluxo de trabalho e gerenciamento de informações relativas aos processos de regulação, avaliação e supervisão da educação superior no sistema federal de educação, e o Cadastro e-MEC de Instituições e Cursos Superiores e consolida disposições sobre indicadores de qualidade, banco de avaliadores (Basis) e o Exame Nacional de Desempenho de Estudantes (Enade) e outras disposições. Republicada por ter saído, no DOU n 239, de 13-12-2007, Seção 1, p. 39-43, com incorreção no original. Brasília, DF: Diário Oficial da União.

Portaria Ministerial $n^{\circ} 555$, de 5 de junho de 2007, prorrogada pela Portaria $n^{\circ}$ 948, de 09 de outubro de 2007. Documento elaborado 
pelo Grupo de Trabalho nomeado pelo Ministério da Educação, Secretaria de Educação Especial (2007) para elaborar a Política Nacional de Educação Especial na Perspectiva da Educação Inclusiva. Brasília: Ministério da Educação. Recuperado em jan 2018. Disponível: http://portal.mec.gov.br/seesp/arquivos/pdf/ politica.pdf

Resolução $n^{\circ}$ 4, de 2 de outubro de 2009. Institui as Diretrizes Operacionais para a Educação Especial na Educação Básica, modalidade Educação Especial. Ministério da Educação. Conselho Nacional de Educação. Câmara de Educação Básica. (2009). Recuperado: 15 maio 2017. Disponível: http://portal.mec. gov.br/dmdocuments/rceb004_09.pdf

Santana, A.P.O.; Donida, L.O.; Pottmeier, S. (2016). Relatório de Dados do Mapeamento da Universidade Federal de Santa Catarina (UFSC) - Alunos da Graduação. Pós-Graduação e Servidores com Deficiência e/ou Transtornos Funcionais (2013-2016).

São Paulo (Estado). Secretaria da Educação. (2012). Legislação de Ensino Fundamental e Médio. São Paulo, SE/CG, v. 39.
Silva, K. C. (2016). Condições de Acessibilidade na Universidade: o ponto de vista de estudantes com deficiência. Dissertação de Mestrado em Educação, Universidade Estadual Paulista, Faculdade de Filosofia e Ciências, Marília.

UNESP. (2015). Anuário Estatístico da Universidade Estadual Paulista "Júlio de Mesquita Filho" (vol. 1). São Paulo: UNESP, APE. Recuperado: 1 jul. 2016. Disponível: https://ape.unesp.br/ anuario/pdf/Anuario2015_NOVO.pdf.

UNESP. (2016). Anuário Estatístico da Universidade Estadual Paulista "Júlio de Mesquita Filho" (Vol. 1). São Paulo: UNESP, APE. Recuperado: 1 jul. 2016 Disponível: https://ape.unesp.br/ anuario/pdf/Anuario_2016.pdf.

License information: This is an open-access article distributed under the terms of the Creative Commons Attribution License (type CC$\mathrm{BY}$ ), which permits unrestricted use,distribution and reproduction in any medium, provided the original article is properly cited.

\section{Sobre as autoras}

Sandra Eli Sartoreto de Oliveira Martins (sandreli@marilia.unesp.br)

Professora assistente doutora do Departamento de Educação Especial e do Programa de Pós-Graduação em Educação, da Faculdade de Filosofia e Ciências da Universidade Estadual Paulista - Unesp, Campus de Marília. http://orcid.org/0000-0002-4247-1447

Lucia Pereira Leite (lucialeite@fc.unesp.br)

Docente do Departamento de Psicologia e Programa Pós-graduação em Psicologia do Desenvolvimento e da Aprendizagem - Unesp/Bauru. http://orcid.org/0000-0003-2401-926x)

Ana Paula Camilo Ciantelli (aninhaciantelli@gmail.com)

Doutoranda no Programa de Pós-graduação em Psicologia do Desenvolvimento e da Aprendizagem, da Faculdade de Ciências - UNESP/Bauru. Bolsista Capes. http://orcid.org/0000-0003-3605-6009) 